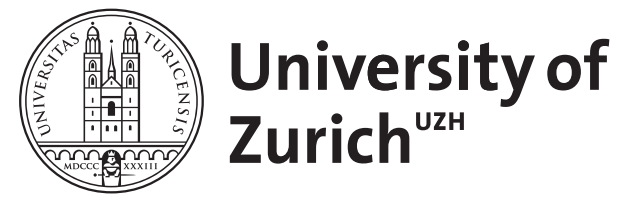

A global biodiversity fund to implement distributive justice for genetic resources

\author{
Deplazes-Zemp, Anna
}

DOI: https://doi.org/10.1111/dewb.12230

Posted at the Zurich Open Repository and Archive, University of Zurich ZORA URL: https://doi.org/10.5167/uzh-170937

Journal Article

Published Version

Originally published at:

Deplazes-Zemp, Anna (2019). A global biodiversity fund to implement distributive justice for genetic resources. Developing World Bioethics, 19(4):235-244.

DOI: https://doi.org/10.1111/dewb.12230 


\section{A global biodiversity fund to implement distributive justice for genetic resources}

\section{Anna Deplazes-Zemp (i)}

\section{Correspondence}

Anna Deplazes-Zemp, University of

Zurich Ethics Research Institute, Zurich, Switzerland.

Email: deplazes@ethik.uzh.ch

\begin{abstract}
This article examines the question of who has a right to control and benefit from genetic resources globally. To this end it draws on different accounts in the resource rights literature with a focus on the specific features that distinguish genetic resources from other types of natural resources. It will be argued that due to the intangible and non-territorial nature of genetic resources, territorial rights over these resources are difficult to maintain. Moreover, the vulnerability of genetic resources implies that much cost and effort is required to protect them. I will argue that not only benefits resulting from the use of genetic resources but also these costs associated with their protection should be an object of distributive justice. To accommodate these two points I will introduce the model of a global biodiversity fund that could replace the bilateral access and benefit sharing negotiations suggested by the Convention on Biological Diversity.
\end{abstract}

\section{KEYWORDS}

Convention on Biological Diversity, distributive justice, genetic resources, global fund, resource rights, territorial rights

\section{1 | INTRODUCTION}

Global inequalities regarding wealth, opportunities and power are amongst the greatest challenges addressed by theories of global and international justice. In this context, control over natural resources and fair distribution of benefits resulting from resource use are central topics. This article addresses these topics with respect to a particular type of natural resources, namely genetic resources. Fair and equitable access and benefit sharing for genetic resources is one of the three key objectives of the UN Convention on Biological Diversity (CBD), ${ }^{1}$ and has been widely discussed not only in the theoretical literature but also at the policy level where it has been implemented as an access and benefit sharing scheme in the Nagoya Protocol (NP). ${ }^{2}$ As noted by

${ }^{1}$ United Nations. (1992). Convention on Biodiversity. Retreived March 7, 2006, from http://www.cbd.int/convention/text/

${ }^{2}$ United Nations. (2010). Nagoya Protocol on Access to Genetic Resources and the Fair and Equitable Sharing of Benefits Arising from their Utilization to the Convention on Biological Diversity. Retreived March 7, 2006 from http://www.cbd.int/abs/doc/proto $\mathrm{col} /$ nagoya-protocol-en.pdf other authors, at least two dimensions of justice have played a role in the interpretation of fair access and benefit sharing for genetic resources in the literature. Echoing Aristotle these two types of justice were described as commutative justice (or justice in exchange) and distributive justice. ${ }^{3,4}$ I elsewhere discussed the access and benefit sharing scheme outlined in the CBD from the point of view of commutative justice. ${ }^{5}$ The article at hand addresses the normative question of how benefits and burdens from genetic resources should be distributed fairly around the globe and thus focuses on distributive justice. By highlighting this justice dimension I do not want to deny that the different justice dimensions are connected. The aim of this paper is to contribute to a better understanding of the ethical challenges related to genetic resources by focusing on one particular justice dimension, in

${ }^{3}$ De Jonge, B., \& Korthals, M. (2006). Vicissitudes of Benefit Sharing of Crop Genetic Resources: Downstream and Upstream. Developing World Bioethics, 6(3), 144-157.

${ }^{4}$ Schroeder, D., \& Lasen-Diaz, C. (2006). Sharing the benefits of genetic resources: from biodiversity to human genetics. Dev World Bioeth, 6(3), 135-143.

${ }^{5}$ Deplazes-Zemp, A. (2018). Commutative Justice and Access and Benefit Sharing for Genetic Resources. Ethics, Policy \& Environment, 21(1), 110-126. 
this case distributive justice, separately. To this end, I will draw on the extensive literature of natural resource justice and examine how the arguments for different types of resource rights can be applied to genetic resources. In doing so, a particular emphasis is set on the features that distinguish genetic resources from other types of natural resources. The article starts with a brief summary of these features followed by an introduction to the natural resource justice literature on which the article builds. I will then present the model of a global biodiversity fund for a fair and equitable distribution of benefits and burdens from genetic resources and discuss it against the background of the current regulatory framework. Finally, the model of a global biodiversity fund will be compared to related suggestions on how to consider distributive justice for genetic resources.

\section{2 | GENETIC RESOURCES AS A PARTICULAR TYPE OF NATURAL RESOURCES}

What are genetic resources and how are they being used? The term 'genetic resources' usually refers to valuable features or capacities of living organisms outlined in their genome, which can be used for various purposes. ${ }^{6}$ Classical examples for the use of genetic resources are so-called bioprospecting projects, which have the aim to develop new drugs based on natural components. In such projects scientists start by collecting genetic resources in the form of samples of a large variety of plants. As a next step, they produce extracts from each of these samples and test them for their effect on cells that serve as a model for a medical condition. If certain extracts show the desired effect, they will be further analysed in order to isolate the effective compound(s), which could eventually lead to a novel drug.

Genetic resources are thus natural resources in the sense that they derive from nature and are instrumental towards satisfying human needs. At the political level too, genetic resources are treated as natural resources and placed under state sovereignty over natural resources, for instance, in the CBD and the NP. These international treaties establish a regulatory framework for fair access and benefit sharing for genetic resources. Two central components of this framework are known as Prior Informed Consent (PIC), and Mutually Agreed Terms (MAT). PIC stands for the requirement that users of genetic resources must inform the provider state about the intended use and can only utilize the genetic resource with the provider's explicit consent. MAT implies that the users of genetic resources negotiate the terms of utilization (including benefits that will be shared) with the provider state.

As natural resources found in living organisms, genetic resources are a type of biological resources. However, genetic resources dispose of special features, which necessitate different treatment and regulation compared to other types of biological resources such as

${ }^{6}$ The CBD defines 'genetic resources' as: "genetic material of actual or potential value" with 'genetic material' as: "any material of plant, animal microbial or other origin containing functional units of heredity". Although this definition is useful to illustrate that it is the genome that is being used, I believe that the reference to 'material' is misleading for reasons that will be outlined in this section. timber or fish. This section briefly summarises four particular characteristics of genetic resources namely that they are informational, non-territorial, vulnerable and non-obvious. ${ }^{7}$

\section{1 | Informational}

When we examine what it is that is being used as a natural resource in the bioprospecting example above, we recognize that it is the information about the composition and the biological production of the compound that could be used to develop a medical treatment. If the bioprospecting project leads to the identification of an effective compound, a company that aims at developing a drug from it, will try to use the biochemical and genetic information to find a way to get the effective compound in great amounts, for instance, by producing it through chemical synthesis, with genetically modified microorganisms or from plants that can be grown in large cultures in the user state. Thereby, the company will not depend on any further material supply of the original plant from the country of origin. The actual natural resource is thus the genetic and biochemical information provided by nature..$^{8,10,11}$ This is a fundamental difference to other biological resources such as fish or timber where it is the material that is being used and which must constantly be imported from the country of origin.

The genetic information could also be used in a breeding process. Let us take the example of a natural apple tree variety carrying a resistant gene against fire blight, a disease that affects apple and pear trees. This resistance could be crossed into commercial varieties. Subsequently, no further supply of the natural variety is required to benefit from this genetic resource. Alternatively, the fire blight resistance gene could be transferred into commercial varieties using tools of genetic engineering again bypassing the need for further supply from the country of origin. These examples show that genetic resources are non-tangible, or in other words, informational. On the one hand, this is illustrated by the independence of material supply. On the other hand, the direct benefits resulting from these genetic resources, namely the resistance to a plant disease or the biochemical information about a compound, are themselves non-material.

\section{2 | Non-territorial}

The non-territorial nature of genetic resources follows from the observation that they are informational. Because the value of genetic resources resides not in their material but in the genetic information, only a small material sample is required to derive benefits from these resources. This could be a leaf to extract genetic information in the

\footnotetext{
${ }^{7}$ These features were introduced in more detail in: Deplazes-Zemp, A. (2018). 'Genetic resources', an analysis of a multifaceted concept. Biological Conservation, 222, 86-94

${ }^{8}$ Deplazes-Zemp, A. op. cit. note 5.

${ }^{9}$ Deplazes-Zemp, A. op. cit. note 7.

${ }^{10}$ Ruiz Muller, M. (2015). Genetic Resources as Natural Information, Implications for the Convention on Biological Diversity and Nagoya Protocol. London, New York: Earthscan, Routledge.

${ }^{11}$ Vogel, J. H. (1994). Genes for Sale, Privatization as a Conservation Policy. New York, Oxford: Oxford University Press.
} 
bioprospecting case above, or a seed to grow future generations of plants. No constant supply from the country of origin is needed. In that sense, the territorial connection is weaker for genetic resources compared to other types of natural resources which are continuously extracted and exported from the country of origin. Most organisms carrying genetic resources occur on the territory of more than one state. However, usually only one state directly contributes the initial material sample of a genetic resource to the development of a product. This is again in contrast to territorial natural resources, where all states with occurrences of the resource in question will have the opportunity to supply their resources for the development of future products.

\section{3 | Vulnerable}

The likelihood for success of bioprospecting projects increases with the genetic variety that can be tested, or in other words, the higher the level of biodiversity that can be explored, the more promising is the project. The phrase 'genetic resources' is used as an appreciation of the instrumental value of biodiversity. In case of bioprospecting this value lies in the unknown potential of individual genes or species that are part of this biodiversity. Moreover, biodiversity itself can be the source of new valuable genes, species or ecosystems and the source of resilience that allows species or ecosystems to adapt to changes and novel challenges in their environment. If we look at genetic resources as biodiversity we become aware of the fact that this type of resources is particularly vulnerable to decimation and extinction. The main threat for genetic resources does not consist in over-exploitation, as it is the case for other natural resources, but in their sensitivity to environmental change and degradation. While they share this feature with material biological resources such as fish and timber, they are even more vulnerable because different species and ecosystems are sensible to different factors and effects. Protecting genetic resources is a more 'holistic' enterprise than protecting singular fish or timber species. The vulnerability of these resources is particularly relevant in an enquiry on distributive justice, because protecting biodiversity requires major investment of effort, time and finances. It will be argued that this burden should be fairly distributed just as much as the benefits resulting from genetic resources.

\section{4 | Non-obvious}

For many traditional natural resources it is evident how they can be used to generate benefits. This is, for instance, true for fish or timber, which are used as nutrition or building material or for ores and gems which as raw material already have a high cultural value. In case of genetic resources the situation is quite different. In order to generate benefits from biodiversity, first, its useful components must be identified and the development into a product is usually not straightforward. For instance, a bioprospecting project with the aim to develop a drug based on a natural compound depends on human innovation in order to identify potential uses of natural plants. This is followed by further intellectual input into a research and development process to generate a product. The large degree of intellectual contribution required for such a product and the tight nexus between natural contribution and intellectual input are characteristic of genetic resources. This non-obviousness is also essential to understand the unethical dimension of so called biopiracy cases, in which companies used, for instance, traditional knowledge about the medical use of a plant without sharing any benefits with the community who contributed this essential information. In these cases the injustice is that the local community in question was neither acknowledged nor compensated for their intellectual contribution. It is thus rather a case of commutative injustice than distributive injustice and will not be further discussed here. ${ }^{12}$

\section{3 | RESOURCE RIGHTS OVER NATURAL RESOURCES}

Before discussing resource rights for genetic resources I will roughly distinguish between two different accounts of rights to natural resources in general. While these theories can be combined to some degree (as will be discussed at the end of this section) I emphasize their differences for their subsequent application to the case of genetic resources as a particular type of natural resources. Following Margaret Moore and Cara Nine, ${ }^{13,14,15}$ I distinguish between, first, resource right scholars, who focus on territorial rights of political communities and argue that the use of natural resources should be governed by these rights and second, authors, who address rights to natural resources in the framework of cosmopolitan theories. They argue that the distribution of natural resources on earth is arbitrary and that everybody has rights to at least some marginal benefits from these resources. In the following, these two accounts will be briefly introduced.

\section{1 | Territorial accounts - the focus on resource rights as jurisdictional rights}

Theorists such as John Rawls, David Miller, Margaret Moore, Cara Nine and many others discuss rights to natural resources as territorial rights. They usually address the question of authority over natural resources and ask who legitimately has a right to govern them. The main focus is thus on the interpretation of resource rights as jurisdictional rights in the sense of self-governance rights although collective property rights also play a role. ${ }^{16}$ These scholars develop different arguments explaining why certain political communities have morally legitimate rights to govern natural resources on their territory. Chris Armstrong distinguishes between indirect and direct

\footnotetext{
${ }^{12}$ But see: Deplazes-Zemp, op. cit. note 5, for further discussion.

${ }^{13}$ Moore, M. (2012). Natural Resources, Territorial Right, and Global Distributive Justice. Political Theory, 40, 84-107.

${ }^{14}$ Moore, M. (2015). A Political Theory of Territory. Oxford: Oxford University Press.

${ }^{15}$ Nine, C. (2012). Global Justice \& Territory. Oxford: Oxford University Press.

${ }^{16}$ Ibid: $116 f f$.
} 
claims to natural resources in territorial accounts. He speaks of indirect claims, when rights to natural resources derive from other prior territorial rights to control borders or territory. In contrast, direct claims to resources derive from a direct relation that those who occupy a territory have to the resources localized on their ground. ${ }^{17,18}$ Three types of arguments could legitimize resource rights as territorial rights based on direct claims to resources. First, it has been suggested that a political community improves or even creates the value of the resources in the territory that it occupies. In his criticism of territorial resource rights Armstrong speaks of "improvement-based special claims". ${ }^{19,20}$ The second type of reasoning refers to what Armstrong calls: "attachment-based special claims". $21,22,23$ It is argued that resource rights are justified by a special attachment through history, customs, culture or religion to the resources in question. The third argument for direct territorial claims to natural resources has, for instance, been invoked by Margaret Moore. She argues that control over natural resources is instrumental for selfdetermination of the community that occupies a territory because the life of this community is affected by rules around the extraction and use of resources localized on the respective territory. Moore highlights that different communities vary in how they value different handlings of natural resources. ${ }^{24}$ I discuss this argument as another suggestion of territorial resource rights that is based (at least partially) on direct and not only on indirect claims to natural resources because it also seems to be the particular relation that these communities have to the resources on their territory, which is relevant for their role in self-determination. This relation is, however, not necessarily an attachment and thus different from the second argument.

\subsection{Cosmopolitan accounts - the focus of resource rights as property rights}

In contradiction to the territorial positions, cosmopolitan thinkers argue that focusing on resource rights as a type of territorial rights disregards their global impact and context. On that account natural resources are distributive goods. The relevant question is not so much: "Who should govern these resources?" but rather "Who should be able to use them, possess them and benefit from them?" It is the property-right aspect of resource rights that is examined although jurisdictional rights in the sense of global governance over natural resources can play a role too. According to cosmopolitans at

\footnotetext{
${ }^{17}$ Armstrong, C. (2014). Against "permanent sovereignty" over natural resources. Politics Philosophy Economics, 1-23.

${ }^{18}$ Armstrong, C. (2017). Justice and Natural Resources, An Egalitarian Theory. Oxford: Oxford University Press, p 118.

${ }^{19}$ Armstrong, C. op. cit. note 17.

${ }^{20}$ Armstrong, C. op. cit. note 18, pp $134 \mathrm{ff}$.

${ }^{21}$ Ibid: $113 \mathrm{ff}$

${ }^{22}$ Armstrong, C. op. cit. note 17.

${ }^{23}$ Armstrong, C. (2014b). Justice and Attachment to Natural Resources. The Journal of Political Philosophy, 22(1), 48-65.

${ }^{24}$ Moore, M. op. cit. note 14, p 166
}

least certain property rights should be shared worldwide. There are stronger and weaker versions of cosmopolitan accounts. Strong interpretations hold that the full value of natural resources should be subject to distribution. Hillel Steiner, for instance, argues based on a luck egalitarian approach that disadvantages resulting from brute luck must be eliminated. He consequently argues for redistribution of the unequal shares of natural resources that people have received by luck. ${ }^{25}$

On a weaker cosmopolitan account, the aim of global redistribution, does not amount to global distributive equality. Instead, such theories aim at ensuring that everybody on this planet can lead a minimally decent life. In that sense, for instance, Gillian Brock argues for a needs-based minimum floor principle, according to which distributive justice requires that people can meet their basic needs. ${ }^{26}$ Another author with a weak cosmopolitan approach is Thomas Pogge, who suggests that the population in affluent developed countries have responsibilities towards improving the miseries suffered by the global poor. One of the reasons for the existing inequality is that some enjoy significant advantages from natural resources whereas others are excluded from these benefits. The advantaged consequently have a moral duty to take measures towards letting the disadvantaged have a share in the profits realized from natural resources. ${ }^{27}$

In spite of the different foundations of their cosmopolitan theories, several authors suggested a global tax or fund as an apt tool towards distributive justice. According to Hillel Steiner's luck egalitarian model, everybody has an original right to a global average of natural resources. Those who use more than their share must pay the difference into a global fund, which serves as a 'redress fund' to compensate those, who use less than their share. Interestingly, Steiner explicitly extends his understanding of natural resources to include genetic resources. ${ }^{28}$ The Global Resources Dividend (GRD), introduced by Thomas Pogge, is a widely noted suggestion of a global tax on benefits from natural resources. Pogge speaks of a moderate proposal because, unlike Steiner, he does not aim at an equal distribution of the full value of natural resources. He acknowledges a right of nation states to control extraction and the use of natural resources within their territory. Nevertheless, he states that "the global poor own an inalienable stake in all limited natural resources" 29 and those who extract these resources and profit from them must pay what he calls a dividend rather than a tax to acknowledge this ownership. The dividend should be paid into a global fund, which will be disbursed to poor nations. Gillian Brock discusses a set of examples for global taxes such as the carbon tax or currency transaction tax (Tobin tax) that have been suggested or even implemented in a limited number

\footnotetext{
${ }^{25}$ Steiner, H. (1994). An Essay on Rights. Oxford: Blackwell Publishers, pp $266 f f$.

${ }^{26}$ Brock, G. (2009). Global Justice, A Cosmopolitan Account. Oxford: Oxford University Press, pp $45 \mathrm{ff}$.

${ }^{27}$ Pogge, T. (2002). World Poverty and Human Rights. Cambridge, Malden: Polity Press

${ }^{28}$ Steiner, H. op. cit. note 25 , however, unlike the discussion of genetic resources in the context of biodiversity, Steiner includes the human genome in his concept of genetic resources.

${ }^{29}$ Pogge, T. op. cit. note 27, p 202
} 
of states. ${ }^{30}$ These examples show that the idea of a global tax is realistic and not simply a matter of theoretical deliberation.

With the separation of these two accounts I've attempted to illustrate differences in starting questions and emphases. However, I am well aware that it would be misleading to present them as incompatible alternatives. For instance, Margaret Moore's territorial theory allows, or even requires, to take into account questions of unjust distribution that characterizes the current state of the globe. ${ }^{31}$ On the other side, Thomas Pogge argues that his requirement for a GRD does not question the rights of national governments to control resources within their territory. ${ }^{32}$ An understanding of resource rights as a bundle of rights, which includes different jurisdictional rights and different property rights ${ }^{33,34,35}$ can facilitate the combination of elements of the two approaches. Certain jurisdictional resource rights can be assigned to specific political communities while some property resource rights are attributed, in a cosmopolitan sense, to all people or political communities worldwide.

\section{4 | TERRITORIAL RESOURCE RIGHTS FOR GENETIC RESOURCES}

As it is the aim of this article to examine what type of resource rights could be justified for genetic resources, the two accounts presented in the previous section will now be applied to the specific case of genetic resources and analysed regarding the particular features of this type of resources.

To what extent can arguments for territorial rights be applied to genetic resources? The description of genetic resources as 'non-territorial' might in itself suffice to reject the idea of territorial rights over genetic resources. As outlined before, the informational nature of these resources weakens their connection to the territory, from which an original material sample has been removed. This point can be elaborated by examining whether the three justifications for direct claims to natural resources introduced earlier can be applied to the case of genetic resources.

The first justification referred to improvement-based special claims. The non-obviousness of genetic resources, which comes with a requirement for high intellectual contribution to generate products, indeed indicates that improvement-based claims might play a role. However, it is not the provider countries, on the territory of which genetic resources were found, that could appeal to such improvement-based claims but exactly their counterparts namely the users of genetic resources. It is in user countries, where the potential of these resources is investigated and improved even before industrial manufacturing of the final product sets in. This 'improvement'

\footnotetext{
${ }^{30}$ Brock, G. op. cit. note 26, pp $131 \mathrm{ff}$.

${ }^{31}$ Moore, M. op. cit. note 13 .

${ }^{32}$ Pogge, T. op. cit. note 27.

${ }^{33}$ Nine, C. op. cit. note 15 , pp $117 \mathrm{ff}$.

${ }^{34}$ Armstrong, C. op. cit. note 17.

${ }^{35}$ Armstrong, C. op. cit. note 18 , pp $22 \mathrm{f}$.
}

takes place in research and development processes and in procedures to introduce the genetic information into new varieties or to turn it into useful compounds with the means of biochemical procedures. Consequently, if at all, this argument can in itself be invoked to reason against direct claims on genetic resources by the state of origin.

The second argument for direct claims to natural resources referred to attachment-based claims, could they serve as a foundation for territorial rights over genetic resources? If we look at genetic resources as deriving from biodiversity of a certain territory or from singular species as instances of this diversity, it could indeed be argued that they are associated to a particular meaning for a region and that there is a particular attachment. But since this attachment is not based on material utilization, the attachment is not territoryrelated. On this view, strong attachment to biodiversity flagship species such as the Giant Panda, the African Lion or the African Elephant go far beyond their territory of origin. These animals have cultural value also in European countries, for instance, where children grow up with knowledge about these endangered species and with cultural adaptation of them as toys, in picture books, films etc. This generates strong attachment to these species around the globe. Moreover, the use of genetic resources outside the territory of origin generates particular attachment too, which can include emotional attachment and dependence, for instance, when genetic resources are used in research. Research projects can rely on certain species and researchers who study them for years may form a strong attachment to them. To argue for direct territorial claims to genetic resources by referring to attachment is thus not convincing either.

Finally, the third argument for direct claims to natural resource was that they are instrumental for self-determination of the group that occupies a territory because the community occupying the territory is directly affected by rules around the extraction and use of the resource in question. In case of genetic resources 'extraction' of these resources is a one-time event and concerns only a little amount of material, when, for instance, a leaf is removed from the rainforest. The main utilization of these resources takes place elsewhere. As informational resources, genetic resources are nonrivalrous. This means that the use of these resources by one party, for example, as agricultural crops, does not hinder others from using them elsewhere. Therefore, utilization of genetic resources in provider states is not affected by how they are being used in the user state. In sum, extraction of these resources will hardly affect the community in the provider state because of the small amount of material that is required and because utilization of these resources elsewhere will not compromise their use in the state of origin. It is thus unlikely that control over genetic resources plays a central role for self-determination of a community and therefore, the third argument does not provide any convincing justification of direct territorial claims to genetic resources either.

If my rationale so far has been correct, direct territorial claims to genetic resources cannot serve to justify territorial rights to genetic resources. This conclusion may be practically relevant, since the access and benefit sharing scheme for genetic resources implemented in the CBD and the NP seems to be based on the assumption of 
territorial rights for genetic resources as the CBD and NP repeatedly refer to "sovereign rights over natural resources". More will be said about the concept of state sovereignty over genetic resources below.

\section{5 | THE GLOBAL BIODIVERSITY FUND}

After this critical analysis of territorial rights over genetic resources the cosmopolitan argument that there is no good reason why benefits from natural resources should go exclusively to the political community that occupies the territory from which they were extracted, is even stronger for genetic resources compared to other types of natural resources. I will therefore turn to a weak cosmopolitan model of resource rights for genetic resources and suggest an account that draws on Thomas Pogge's GRD. As mentioned earlier, a cosmopolitan account of genetic resource justice is based on the notion that everybody should be able to benefit, at least to some degree, from these natural resources; this argument can also be extended to future generations. However, conservation of genetic resources for the future comes with direct costs generated by conservation projects as well as opportunity costs resulting from the non-use, for instance, of land or timber in areas protected to conserve biodiversity. In his recent book on natural resource justice, Chris Armstrong highlighted that a theory of distributive justice should not only address the distribution of benefits but also of burdens. He tackled conservation of natural resources in the sense of protection, restoration and non-exploitation as examples of burdens that accrue in the context of certain natural resources and must be considered. ${ }^{36,37}$ There are probably not many types of natural resources where this connection between benefits and burdens is as direct, tight and weighty as in case of genetic resources, which I previously characterized as vulnerable to decimation and extinction. It is thus a direct matter of distributive justice that not only positive but also negative implications of biodiversity are being shared fairly and that members of current generations ensure that future generations can enjoy their share in benefits from genetic resources. This means that to safeguard this share, we have the common responsibility to maintain and protect biodiversity; rights to benefits from genetic resources are thus coupled with duties to protect them. ${ }^{38}$

\footnotetext{
${ }^{36}$ Armstrong, C. op. cit. note 18, pp $220 \mathrm{ff}$.

${ }^{37}$ Fair distribution of environmental burdens is a topic prominently addressed in the field of environmental justice, see: Walker, G. (2012). Environmental Justice, Concepts, Evidence and Politics. London, New York: Routledge.

This might be another interesting justice perspective on genetic resources, in which distributive justice aspects come together with justice as recognition, which Gordon Walker defines as "justice conceived in terms of who is given respect and who is and isn't valued" (Ibid: 10). Traditionally, the environmental justice literature seems to focus on environmental burdens such as pollution, flooding or noise rather than the requirement for biodiversity conservation.

${ }^{38}$ In addition, the connection between rights to benefits and duties to protect could also be understood as a matter of commutative justice, meaning that those who profit from genetic resources should pay back into the protection of nature as a compensation for nature's contribution, which the users received for free.
}

I attempt to establish the nexus between rights and duties associated with genetic resources with the model of a global biodiversity fund, which is supplied by a levy on revenues from genetic resources. This fund should then be used to support biodiversity conservation projects in order to contribute to the fair distribution of the burdens arising from genetic resources. I will start with some remarks on how shares in benefits from genetic resources could go into the fund before I will say something about how revenues could be disbursed from the fund.

Contributions to the global biodiversity fund should not simply be paid as a gesture of solidarity or to discourage certain practices as many of the global taxes discussed by Gillian Brock. For instance, the carbon tax or currency transaction tax (Tobin tax) have been developed primarily in order to discourage those activities on which the taxes have been imposed. ${ }^{39}$ Instead, contributions to the global biodiversity fund are morally required on grounds of distributive justice. The requirement to pay into this fund does not only apply to users that directly import genetic resources from provider states but it includes those who use genetic resources in their own country, be it from collections or from their own natural environment. These users also benefit from genetic information as a natural resource, and thus should contribute to the global biodiversity fund. The model is cosmopolitan in a weak sense because it does not require that the entire value of genetic resources should be equally divided amongst the global population, as suggested, for instance, by Hillel Steiner. I follow Pogge and other cosmopolitan authors such as Brock or Chok Tan ${ }^{40,41,42}$ in the assumption that, even if direct territorial claims to natural resources are denied states fulfil important functions for their citizens and a global international organisation is desirable and practically necessary. ${ }^{43}$ States thus play certain roles in the model of the global biodiversity fund. The regulation of access and benefit sharing for genetic resources has, so far, been discussed at the level of the United Nations and the CBD provides an existing framework for dealing with distributive justice for genetic resources. It makes sense to locate the global biodiversity fund at this existing intergovernmental institution with states as acting parties. Echoing Pogge's suggestion, it could thus be states rather than single companies that pay into the global fund. In this case, states would pay the dividend on the financial profits made from genetic resources on their territory and they would levy taxes, which they can use to pay the contribution to the global biodiversity fund. In order to warrant tax autonomy of sovereign states, it could be left to the state whether it charges the full amount of the revenues for the fund on the users or whether the state subsidizes part of this amount from other revenues. The amount of the tax, like the contribution to the fund

\footnotetext{
${ }^{39}$ Brock, G. op. cit. note 26, pp $131 \mathrm{ff}$.

${ }^{40}$ Ibid

${ }^{41}$ Pogge, T. op. cit. note 27.

${ }^{42}$ Tan, K.-C. (2004). Justice without Borders, Cosmopolitanism, Nationalism and Patriotism. Cambridge: Cambridge University Press.

${ }^{43}$ This is not to deny that in certain cases, states do not perform their functions properly, for instance, when minority groups on state territory are being oppressed.
} 
itself, should depend on the profit made from the genetic resources in question. Possibly a modest and standardized contribution to the fund from all research institutions working with biological material could also be required to acknowledge the importance of biodiversity for biological research.

This brings me to the second aspect of distributive justice that is tackled by the global biodiversity fund, namely the distribution of the burden of biodiversity conservation. Assuming that such a global biodiversity fund were established, the question arises, how its revenues would be disbursed. To implementing distributive justice I suggest three overarching principles: first, the fund should be used to ensure effective biodiversity protection to optimize its impact on distributive justice. It therefore should be used for particularly promising and sustainable biodiversity conservation projects. Second, the revenues should be disbursed such that those who have profited least from genetic resources and/or to whom highest conservation costs accrue will benefit most from the fund, because the aim of disbursement should be to contribute to levelling out existing inequality concerning benefits and burdens. This means that usually projects involving low-income countries in biodiversity rich regions should be treated with priority because they carry the highest burden of conservation. However, certain projects should also be established in low-income regions with lower biodiversity, which also needs protection. Third, to ensure that distributive justice reaches not only states and institutions but people, projects should consider the well-being of those affected and involved by conservation projects in the implementation of the first two principles. Burdens that such projects might charge on local communities should be reduced and affected communities should benefit from these projects. As a general direction I would suggest, in deviation to Pogge's model, that the funds should rather go into individual biodiversity projects than to state governments. The reason for this is pragmatic because it seems to be a more efficient mechanism to ensure optimal distribution, conservation and beneficence. By a project-based disbursement scheme it seems, for instance, to be easier to strengthen international collaborations between citizens in biodiversity rich and infrastructure rich states and incentivise the development of concrete conservation projects that take into account needs of local communities.

It is clear that the global biodiversity fund will, by far, not suffice to cover all costs of biodiversity conservation, hence there is a need for additional contributions. To decide about the distribution of additional costs, other principles such as the 'ability to pay' principle and the 'contributor pays' principle might be consulted. ${ }^{44}$ The first suggests that burdens should be distributed according to the ability to bear them. The latter, which in the context of climate change is often called polluter pays principle, suggests that those who have contributed most to the causes for biodiversity loss should bear the burden of conservation.

Some cosmopolitan scholars might criticize that the account of the global biodiversity fund dismisses the purpose of contributing to distributive justice because the fund is not directly used to

\footnotetext{
${ }^{44}$ Armstrong, C. op. cit. note 18 , pp 220 ff.
}

combat poverty. I would respond by highlighting that poverty cannot only be combated by disbursement of benefits but also by reducing expenses, which is what the suggested fund is supposed to do by addressing the unfair distribution of environmental costs. Moreover, financial contributions to environmental programmes ideally produce employment and other opportunities for the local population. The aim of combatting poverty should thus not be seen as an alternative to biodiversity conservation. This is not the place to develop detailed strategies of how to combine the two agendas but poverty alleviation by supporting sustainable development, for instance, by providing incentives against ecologically harmful practices could be a sensible approach. ${ }^{45}$ It could still be criticized that people in areas with low biodiversity will not be able to profit from this global fund. As mentioned above, also regions with lower biodiversity should be considered, but since less conservation costs accrue to these regions, it seems to be justified that fewer projects will be allocated to them.

Others may object that this model only takes into account monetary benefits from genetic resources and neglects, for instance, the non-monetary benefits listed in the Annex of the NP. It is true that this model does not consider non-monetary benefits such as research collaborations, participation in product development, or training for research partners with less elaborated university systems. It is clearly important to share these types of benefits too. However, as these benefits are in no way specific to projects involving genetic resources they should be shared in all research collaborations between research institutions in affluent and poor states. Other non-monetary benefits mentioned in the NP such as capacity building, education, food and livelihood security benefits, or social recognition are based on basic rights that should be granted to citizens of all states and not be bound to negotiations on the use of genetic resources. Non-monetary benefits resulting from the use of genetic resources should thus be addressed by other schemes that take into account the particular underlying claims and nature of these benefits and that extend to cases, in which the same type of benefits occur independently of any use of genetic resources. ${ }^{46}$

\subsection{Integrating the global biodiversity fund into the CBD}

Although the global biodiversity fund model presented in this article is rudimentary and can only suggest a general direction towards distributive justice for genetic resources, the aim is to present something that could be practically implemented in the future. Therefore, in this section, I will compare this account of

\footnotetext{
${ }^{45}$ Ruiz Muller, M. op. cit. note 10, p 75.

${ }^{46}$ This article thus discusses distributive justice in a narrower sense than De Jonge and Korthals and does not include what these authors call "upstream benefit sharing", which involves, for instance, fair distribution of opportunities to determine research agendas and priorities De Jonge, B., \& Korthals, M. op. cit. note 3.). These are clearly essential issues that must be addressed, but for which the global biodiversity fund suggested here is not the right approach. In accordance with what was said before, I would argue that fair distribution of upstream benefits should be addressed with a broader scope and not be limited to the context of genetic resources.
} 
how benefits from genetic resources could be shared with the regulatory framework of access and benefit sharing outlined by the CBD and the component NP. The access and benefit sharing scheme established in the NP has been developed to address the unfair situation that companies in economically rich biodiversity poor states benefit from using genetic resources while low income states rich in biodiversity bear the burden of biodiversity conservation. The current scheme requires that biodiversity rich states providing genetic resources must be informed and give consent to the use of 'their' genetic resources and that users of genetic resources should share some of their benefits with the provider states. However, as argued above, this model seems to be based on questionable territorial claims of provider states. The global biodiversity fund suggested here, pursues the same aim towards more distributive justice for benefits and burdens associated with genetic resources as the CBD without relying on these questionable claims. Moreover, it shares the aim of the CBD to discuss benefits from genetic resources alongside with responsibilities to protect biodiversity. A global biodiversity fund as envisioned here even tightens this link compared to the access and benefit sharing framework outlined in the CBD and NP, which, in spite of mentioning both benefits and responsibilities, does not emphasize their connection. Article 9 of the NP merely suggests that parties should encourage (rather than oblige) users and providers of genetic resources to use benefits towards conservation of biodiversity and sustainable development. The global biodiversity fund makes this connection mandatory by requiring that disbursements be used for biodiversity conservation projects.

Integrating the global biodiversity fund into an international convention needs to be compatible with an understanding of states as sovereign parties. The question arises, whether the account of a global biodiversity fund with its criticism of territorial rights over genetic resources allows for this. It is true that the CBD and NP repeatedly refer to "sovereign rights over natural resources". However, a close reading of the two treaties reveals that they refer to state sovereignty over natural resources to explain the right of states to control access to genetic resources but not directly to explain that states have claims to a share in benefits. ${ }^{47}$ Exclusive territorial rights to a share in benefits from non-territorial natural resources need to be legitimated by direct claims to natural resources because there is no connection between the genetic resource and the territory of the provider state after the moment when a small material sample carrying the genetic resource has been removed. However, territorial rights to control access to this material sample on the provider state's territory are legitimized by other territorial rights of controlling the borders of state territory and actions that take place therein, one could thus speak of indirect claims to genetic resources. The account presented here does not question states' jurisdictional rights of

\footnotetext{
${ }^{47}$ It is not clear from the texts of CBD and NP how the requirement to share benefits resources is ethically justified. The strong emphasis on fairness and equitability may indicate an underlying aim of contributing to distributive justice, however the tight link between providing access to resources and sharing benefits from them may be understood as an argument of commutative justice rather than distributive justice.
}

governing access to state territory. State sovereignty over genetic resources would thus be interpreted in a weak sense as the right of governing access to territory and actions that take place therein including the removal from material carrying genetic resources. To acknowledge territorial rights of non-state nations, this account could include a requirement to consider local and indigenous communities, for instance, by obtaining their prior informed consent (PIC). However, in contrast to the requirements in the CBD and NP, PIC would only be required for access to the territory occupied by the respective communities or states and the actions taking place there and could probably be obtained using a standardised procedure. It would not extent to how these resources are being used after they have been exported. ${ }^{48}$ This model thus suggests that just access to genetic resources should be regulated independently of just sharing of benefits from utilizing them, for which the fund would be implemented.

Finally, the account of a global biodiversity fund is not only compatible with the CBD it would also highly profit from its institutional framework, which could host the global biodiversity fund and ensure fair disbursement of its content.

\subsection{Comparison to other models for global funds for genetic resource benefits}

There have been previous suggestions of global funds for genetic resource benefits in different practical and theoretical contexts. In the following, I would like to briefly outline these alternative models and highlight the differences to the account presented here.

The most advanced suggestion has been successfully implemented for agricultural plant genetic resources within the so-called Multilateral System (MLS) of the International Treaty on Plant Genetic Resources for Food and Agriculture (ITPGRFA). The MLS provides an access and benefit sharing system for 64 of the most important crops. States ratifying the ITPGRFA commit to making 'their' genetic material of these 64 crops easily accessible for users through collections in the world's gene banks. To access these resources users would only have to complete a simple Standard Material Transfer Agreement using a template instead of entering individual PIC and MAT procedures for each project. In return, for receiving simplified access to these genetic resources, users must make developments resulting from their utilization freely accessible or a percentage of the benefits must be paid into a common fund. According to the MLS this fund, which was established in 2008 , is intended "to support conservation and further development of agriculture in the developing world" ${ }^{49}$ Comparable to the account of a

\footnotetext{
${ }^{48}$ For a related criticism of the concept of 'state sovereignty over genetic resources' see: Brody, B. A. (2010). Intellectual Property, State Sovereignty, and Biotechnology. Kennedy Institute of Ethics Journal, 20(1), 51-73.

${ }^{49}$ Food and Agriculture Organization of the United Nations. International Treaty on Plant Genetic Resources for Food and Agriculture, The Multilateral System. Retreived March 7 , 2019 from http://www.fao.org/plant-treaty/areas-of-work/the-multilateral-system/ overview/en/
} 
global biodiversity fund also the MLS thus directs benefits from genetic resources towards biodiversity conservation projects albeit with a focus on agricultural plants. The MLS goes further than my account by regulating not only benefit sharing but also access to these resources by requiring that they be accessible in a collection. Unlike the account presented in this paper, the MLS is restricted to a limited number of genetic resources, namely the 64 most important crops. The requirement of access and benefit sharing for these crops is justified with the central role that these plants play for global food security rather than with the importance of fair distribution of benefits from natural resources. In spite of differences in scope, legitimation and realization of this model, it is encouraging because it shows that the idea of a global fund can be implemented in the real world.

Interestingly the NP itself refers to a mechanism that could be used to implement a global fund. Article 10 refers to a global multilateral benefit sharing mechanism for the sharing of benefits in cases of genetic resources that occur in transboundary situations or when, for practical reasons, PIC cannot be obtained. It is explicitly noted that benefits shared through this mechanism should be used to support biodiversity conservation. Although the details of the implementation of such a mechanism remain vague and it has only been envisaged for exceptional situations, this article may be read as an indication for the compatibility of a global fund with the CBD.

This is also the reading suggested by Manuel Ruiz Muller, who drawing on the groundwork by Joseph Henry Vogel- suggested a detailed account of a global benefit sharing fund for genetic resources. ${ }^{50}$

,51 In accordance with my account Vogel and Ruiz Muller aim at ensuring that benefits from genetic resources go into conservation of biodiversity and more importantly, they also start from the observation that genetic resources are non-tangible but informational. However, in contrast to this article, which starts from theoretical reflections on distributive justice and resource rights for genetic resources, Vogel and Ruiz Muller start from a pragmatic economic position. They argue that a global fund would be a more suitable and efficient way of providing financial incentives towards biodiversity conservation than the CBD's access and benefit-sharing system. Ruiz Muller reasons that because genetic resources are informational, all states on the territory of which the respective genetic resource (usually species) occurs, must receive a share in benefits, therefore, most cases fulfil the conditions of a 'transboundary situation' as outlined in NP article $10 .{ }^{52}$ Vogel and Ruiz Muller suggest that those who profit financially from genetic resources should pay into a global fund and the states with occurrences of the resource in question would receive a share of these financial benefits. The authors argue that this would provide an incentive to protect biodiversity and ensure that efforts are made to maintain many species on state territory. ${ }^{53}$ The main difference to the account suggested in this paper is, that Vogel and Ruiz Muller adhere to territorial claims to

\footnotetext{
${ }^{50}$ Ruiz Muller, M. op. cit. note 10

${ }^{51}$ Vogel, J. H. op. cit. note 11.

${ }^{52}$ United Nations. op. cit. note 2

${ }^{53}$ Ruiz Muller, M. op. cit. note 10.
}

genetic resources of the states of origin although they widen the concept of state of origin from 'state that provided the original material sample' to 'all states on which this instance of biodiversity occurs' (my phrasing). They maintain that the fund should be disbursed to those countries with particular territorial rights to their genetic resources rather than as a matter of global distributive justice for benefits from genetic resources.

These examples show that the idea of a global biodiversity fund is not only supported by arguments of distributive justice but that there are also pragmatic arguments in its favour. An additional practical advantage pointed out by the discussed models is that a global biodiversity fund scheme would circumvent the high administrative workload associated with the current access and benefit sharing scheme, which has been critically discussed as a potential hindrance of non-commercial research involving genetic resources. ${ }^{54,55,56}$ The administrative burden could be reduced because in contrast to the CBD's scheme the global biodiversity fund model does not rely on obtaining PIC and negotiating MAT for how genetic resources are being used outside the territory of the provider state. This does not exempt those who wish to export biological material from the requirement of getting permission to access state territory and export material biological samples. However, the individualized PIC and MAT procedures could probably be replaced by standardised entry and export permits because usually only small biological samples are required that can be gained without any lasting impact on the place of origin.

\section{6 | SUMMARY AND CONCLUSION}

It was one of the aims of the $C B D$ and the NP to ensure fairness and equity with respect to how benefits from the use of genetic resources are being shared globally and this against a background of requiring that all countries contribute to conserving genetic resources as biodiversity.

The question of who should be able to profit from natural resources in general, has been debated intensely. This article roughly distinguished between two accounts: A territorial approach, that conceives of resource rights primarily as jurisdictional rights held by nations, and a cosmopolitan approach that understands resource rights as a type of property rights that are not dependent on territorial borders. To explore to what extent these theories can be applied to genetic resources, it is important to accommodate the features that distinguish this type of natural resources from others, namely that genetic resources are informational, non-territorial, their use is non-obvious and they are vulnerable to decimation and extinction. These features are essential for my arguments against direct territorial claims by provider states to benefits from genetic resources and

\footnotetext{
${ }^{54}$ Deplazes-Zemp, A., et al. (2018). The Nagoya Protocol could backfire on the Global South. Nat Ecol Evol, 2(6), 917-919.

${ }^{55}$ Martinez, S. I., \& Biber-Klemm, S. (2010). Scientists-take action for access to biodiversity. Current Opinion in Environmental Sustainability, 2, 1-7.

${ }^{56}$ Schindel, D. E. (2010). Biology without borders. Nature, 467(7317), 779-781.
} 
for the particular importance of relating the distribution of benefits from these resources to the distribution of costs for conserving them. I suggested that such a relation can be implemented in a global biodiversity fund, which is supplied by levies on benefits from genetic resources and disbursed for biodiversity conservation projects. While the current access and benefit sharing system in the CBD framework rather seems to be supported by a territorial account of justice over natural resources (in the sense of state sovereignty over natural resources), the main arguments supporting the biodiversity fund model are based on a weak cosmopolitan account. More specifically, the model draws on Pogge's suggestion of a global resource dividend for traditional tangible resources. In Pogge's sense it could be states that pay into the biodiversity fund. This would facilitate the introduction of this fund into the framework of the CBD with states as ratifying parties.

Another difference between the global biodiversity fund and the existing access and benefit sharing framework is that also parties who use genetic resource within the state of origin have to share benefits from these resources. The reason for this is again that this model does not connect benefit sharing to providing access to state territory. Therefore, even in cases, where access and use of genetic resources take place in the same country, there is a requirement for benefit sharing.

As a third difference, this model treats the use of genetic resources as natural resources differently from the use of traditional knowledge associated to these resources. The latter consists in an intellectual contribution and is thus not considered to be subject to resource rights but to the field of commutative justice as I discussed elsewhere. ${ }^{57}$ Local and indigenous communities will not loose weight in the new framework. As it will often be these communities on whom the success of biodiversity conservation depends, they should be amongst the main beneficiaries of the global biodiversity fund.

\section{ACKNOWLEDGEMENTS}

Many thanks to Peter Schaber for his helpful input to different versions of this manuscript. An earlier version of the text was presented at the URPP GCB conference at Monte Verita and I would like to thank particularly Margaret Moore, Fabian Schuppert and Jack Williams for their constructive comments. This work was supported by the UZH Research Priority Program (URPP) on 'Global Change and Biodiversity'.

\section{CONFLICT OF INTEREST}

The author declares no conflicts of interest.

\section{ORCID}

Anna Deplazes-Zemp iD https://orcid.org/0000-0002-1992-1622

\section{AUTHOR BIOGRAPHY}

Anna Deplazes-Zemp is a senior researcher at the Ethics Research Institute (ERI) at the University of Zurich. Besides the topic of justice for genetic resources her research interests include environmental ethics (human-nature relationship) the ethics of biotechnology and research ethics with a focus on the moral responsibility of scientists.

How to cite this article: Deplazes-Zemp A. A global biodiversity fund to implement distributive justice for genetic resources. Developing World Bioeth. 2019;00:1-10. https:// doi.org/10.1111/dewb.12230

\footnotetext{
${ }^{57}$ Deplazes-Zemp, op. cit. note 5.
} 